\title{
Review
}

\section{Review of Stereotactic Arrhythmia Radioablation Therapy for Cardiac Tachydysrhythmias}

\author{
Michael H. Chiu, MD, MSc, FRCPC, L. Brent Mitchell, MD, FRCPC, \\ Nicolas Ploquin, PhD, FCCPM, Salman Faruqi, MD, FRCPC, and \\ Vikas P. Kuriachan, MD, FRCPC, FCCS, FHRS, FACC \\ Libin Cardiovascular Institute of Alberta, Department of Cardiac Sciences, University of Calgary and Alberta Health Services, Calgary, Alberta, Canada
}

\begin{abstract}
Cardiac tachyarrhythmias are a major cause of morbidity and mortality. Treatments for these tachyarrhythmias include antiarrhythmic drugs, catheter ablation, surgical ablation, cardiac implantable electronic devices, and cardiac transplantation. Each of these treatment approaches is effective in some patients but there is considerable room for improvement, particularly with respect to the most common of the tachydysrhythmias, atrial fibrillation, and the most dangerous of the tachydysrhythmias, ventricular tachycardia (VT) or ventricular fibrillation. Noninvasive stereotactic ablative radiation therapy is emerging as an effective treatment for refractory tachyarrhythmias.
\end{abstract}

Cardiac tachyarrhythmias are a major cause of morbidity and mortality. When symptomatic, their consequences range from benign spells of supraventricular tachycardia to lifethreatening episodes of ventricular tachycardia (VT) or ventricular fibrillation (VF). VF has been attributed to approximately $20 \%$ of all mortality, requiring intensive intervention for prevention of sudden death. ${ }^{1}$ Treatments are effective in some patients but there is considerable room for improvement, particularly for the most common tachyarrhythmia, atrial fibrillation (AF), and for the most dangerous tachyarrhythmias, VT and VF. Noninvasive ablation using cardiac stereotactic body radiation therapy (SBRT), also known as stereotactic arrhythmia radioablation (STAR), is emerging as a novel treatment approach. In animal models, myocardial substrates of AF, atrial flutter, the atrioventricular node, and VT have been radioablated with

Received for publication June 30, 2020. Accepted November 6, 2020.

Ethics Statement: The research reported adheres to relevant ethical guidelines.

Corresponding author: Dr Michael Chiu, Division of Cardiology, Foothills Hospital, 1403 - 29th Street NW, Calgary, Alberta T2N 2T9, Canada. Tel.: 403-210-6271

E-mail: Michael.chiu@ahs.ca

See page 246 for disclosure information.

\section{RÉSUMÉ}

Les tachyarythmies cardiaques sont une cause importante de morbidité et de mortalité. Les traitements employés comprennent des antiarythmiques, l'ablation par cathéter, l'ablation par chirurgie, l'implantation de dispositifs cardiaques électroniques et la transplantation cardiaque. Toutes ces démarches thérapeutiques sont efficaces dans certains cas, mais les traitements peuvent encore être largement améliorés, en particulier en ce qui concerne la fibrillation auriculaire, qui est la tachyarythmie la plus fréquente, et la tachycardie ventriculaire (TV, aussi appelée fibrillation ventriculaire), qui est la tachyarythmie la plus dangereuse. La radiochirurgie stéréotaxique non

minimal short-term complications. Small studies of STAR in patients with refractory VT have provided promising efficacy and safety data.

In this review, we provide the rationale and indications for STAR and the results of animal and human studies to date.

\section{Current Management of Tachyarrhythmias}

Suppression of cardiac tachyarrhythmias typically begins with antiarrhythmic drugs chosen on the basis of left ventricle (LV) function and history of coronary artery disease. ${ }^{2,3}$ When medical therapy fails, consideration is given to destruction or isolation of the arrhythmogenic substrate using invasive catheter ablation. For complex ablations such as those for $\mathrm{AF}$ or VT, success rates are between $50 \%$ and $70 \%$ with significant complications occurring in $3 \%-5 \%$ of patients. ${ }^{4-6}$ Complex ablations can last from 3 to 8 hours and might require deep sedation or general anesthesia. Lower success rates are seen in patients with abnormal anatomy (either acquired or congenital structural heart disease), procedures requiring $3 \mathrm{D}$ mapping, procedures with targets remote from the endocardium, and procedures with targets close to structures such as the esophagus, phrenic nerves, and the coronary arteries. $^{7-9}$ Finally, many patients with VT/VF have severe 
Animal models have shown successful ablation of arrhythmogenic myocardial substrates with minimal short-term complications. Studies of stereotactic radioablation involving patients with refractory VT have shown a reduction in VT recurrence and promising early safety data. In this review, we provide the background for the application of stereotactic arrhythmia radioablation therapy along with promising results from early applications of the technology. underlying heart disease or comorbidities that preclude their candidacy for catheter ablation. ${ }^{10}$

\section{External Beam Radiation Therapy}

Radiation therapy uses a high dose of radiation to induce damage to a target site, in the case of cancer therapy, by virtue of direct cytotoxicity and inhibition of cell replication. ${ }^{11}$ The goal of radiation therapy is to deliver a therapeutic dose of radiation to a specific area of the body while sparing surrounding healthy tissues. The most common delivery systems are medical linear accelerators (LINACs), which produce photons or electrons; the Gamma Knife system, which produces gamma rays from the Cobalt60 radioactive isotope, and any large-particle accelerator able to produce proton or heavy ions such as carbon ions. Photon radiation therapy is most commonly used; however, charged particles (protons, helium and carbon ions) are also used clinically and for research purposes worldwide. Heavy particles require more complex delivery facilities but have theoretical advantages of higher radiobiologic effectiveness and more precise targeting. Our review will focus on photon radiation therapy.

External beam radiation therapy is delivered from outside of the body using high-energy radiation photons produced by a medical LINAC. ${ }^{19}$ For the purposes of STAR, indirectly ionizing photon radiation therapy is delivered using either a conventional LINAC or a robotic-mounted LINACs such as CyberKnife (Accuray, Sunnyvale, CA), which combines a LINAC, image guidance system, and robotic manipulator. ${ }^{12}$

\section{Proposed mechanisms of action}

When a beam of x-rays exits from a LINAC, a large number of photons with various energies (between 4 and $20 \mathrm{MeV}$ ) interact in a medium in different waysdepending on the energy of the incident photons and the atomic number of the medium. The 4 main type of interactions that occur in the medium are the photoelectric effect, Rayleigh scattering, Compton effect, and pair production. ${ }^{13,14}$ After any of these interactions, the ionizing radiation produced will cause direct or indirect effects on DNA. The direct effects consist of ionization or excitation of electrons within the constituent atoms of the DNA. This in turn damages or disrupts chemical bonds, leading to strand breakage or base damage. The indirect effects consist of interactions with the medium surrounding the DNA to generate free radicals. ${ }^{14}$ Free radicals lead to single- and invasive se démarque de plus en plus comme traitement efficace des tachyarythmies réfractaires. Des substrats myocardiques arythmogènes ont pu être réséqués avec succès sur des modèles animaux, l'intervention n'ayant entraîné que des complications minimales de courte durée. Dans le cadre d'études menées auprès de patients présentant une TV réfractaire, la radiochirurgie stéréotaxique a permis de réduire le risque de récurrence de la TV, et les premières données sur l'innocuité du traitement sont encourageantes. Dans notre revue, nous précisons le cadre d'application de la radiochirurgie stéréotaxique visant à réséquer le tissu responsable de l'arythmie, et nous présentons les résultats prometteurs des premières applications de la technologie à cette fin.

double-stranded DNA breaks. This DNA damage can cause mitotic cell death when cells attempt replication. Normal tissue is more adept at repairing DNA damage than are cancer cells and can repair itself between separate radiation sessions or fractions. This leads to a differential effect of radiation on cancer vs normal tissue called the therapeutic ratio. This form of cell death takes weeks to fully materialize. In the case of STAR, there are no rapidly dividing cells in the target myocardium, so fractionation is less relevant. Nevertheless, ionizing radiation also induces considerable vascular damage and can alter the microenvironment of myocytes, thereby disrupting the mechanisms of tachyarrhythmia. ${ }^{15}$ These effects might include alterations in conduction velocities and refractory periods due to changes in gap junctions and their structural proteins, connexions. ${ }^{16}$

Common radiation therapy treatments are usually delivered in multiple lower dose (approximately 2 Gy) fractions. Recent advances in radiation therapy delivery techniques allow higher doses of radiation per day, termed hypofractionated radiotherapy. The effects of radiation at doses $>10$ Gy per fraction have been shown to induce greater degrees of vascular damage $^{15}$ than conventional radiation, as well as to instigate a strong immune response directed at the target (the abscopal effect). ${ }^{17}$ Animal models have suggested that a difference in cell death is seen in unequal split-dose irradiation, with higher rates of cell death accompanying larger first doses. ${ }^{18}$ Our understanding of the biologic effects of single fraction radiation, as is used in STAR, is continuing to evolve. Its effectiveness might be underestimated by the traditional linear-quadratic model that is used to predict response to conventional radiotherapy.

\section{Delivery of radiation}

Improved imaging and treatment planning software have rapidly advanced radiation therapies. Two-dimensional treatment planning has been replaced by 3D imaging using computed tomography (CT) and magnetic resonance imaging (MRI) localization to effectively focus the radiation at the target. ${ }^{19}$

Radiation oncologists map gross tumour volume (GTV) and delineate a margin of potential microscopic tumour extension to form a clinical target volume. Motion artifacts and variations in margins lead to a planned target volume (PTV), which becomes the target. ${ }^{19}$ Image-guided radiotherapy accounts for organ motion to minimize the radiation 
dose to nearby bystander structures. ${ }^{19}$ These concepts have been transferred from radiation therapy of malignancies to that used for the ablation of the substrates of cardiac tachyarrhythmias. Nevertheless, in contrast to major solid organs, motion is a serious concern in radiotherapy of the heart. Luckily, advancements in the technologies used to plan and deliver radiation have allowed computer-controlled intensity modulation of multiple radiation beams to provide improved therapeutic ratios. ${ }^{19}$ One recent example is the introduction of volumetric modulated arc therapy (VMAT), which allows the simultaneous variation of rotation speed treatment, aperture shape, and dose rate. ${ }^{20}$

\section{SBRT}

SBRT provides high-dose radiation per fraction to a well defined target, reducing the number of treatments required for a definitive course of treatment for malignancies. ${ }^{919}$ Because of the higher dose per fraction typical of SBRT, accurate imaging and advanced treatment planning techniques are needed to provide a conformal dose distribution around the target with rapid dose fall off in adjacent healthy tissue. This is achieved using multiple arcs such as in VMAT. ${ }^{21,22}$ Multiple beam angles are chosen to maximize intersection at the PTV while limiting exposure at entry points and adjacent structures. ${ }^{21}$ This allows for a highly focused and optimized radiation dose to the target site while minimizing off-target exposures (Fig. 1). SBRT is commonly used to treat lung malignancy and is emerging as a standard of care option for solid organ malignancies. ${ }^{21,22}$

\section{Techniques for motion management}

Physiological movement is a common challenge for accurate radiation delivery. Electrocardiogram (ECG)-gated 4dimensional CT has been used to study the heart during a cardiac cycle. Mean values of displacement were up to $4.1 \mathrm{~mm}$ for the LV, with changes in volume of up to $16.5 \%{ }^{23}$ There are 3 approaches to motion compensation-immobilization, target tracking, and gating. ${ }^{21}$ Immobilization can be passive or active. Breath-holding is an example of a passive immobilization; abdominal compression to limit diaphragmatic motion is an example of active immobilization. ${ }^{21,22}$ Foam or air-based immobilization devices are commonly used to keep the patient in position. Compression to the abdomen can be added to this type of immobilization to reduce the motion of organs in the thorax and abdomen. ${ }^{24}$ Gating uses a marker to follow target movement during the respiratory and/or cardiac cycle. ${ }^{3,25}$

Motion tracking and immobilization are critical for SBRT targeting myocardial tissue, because cardiac structures have physiologic movements associated with respiratory inspiration, respiratory expiration, myocardial contraction, and myocardial relaxation. Furthermore, adjacent bystander structures at risk of radiation injury are also in motion. These include: heart valves, coronary arteries, esophagus, phrenic nerves, lung parenchyma, pericardium, and atrial tissue. ${ }^{26}$

Two main types of fixation devices have been used in clinical SBRT procedures. A vacuum-assisted cushion formed to the patient body (BodyFIX; Elekta, Stockholm, Sweden) or a foam cushion (Alpha Cradle; Smithers Medical Products,
North Canton, $\mathrm{OH}$ ) coupled with abdominal compression (FreedomX; CDR Systems, Calgary, Alberta, Canada). Respiration-correlated CT provides cardiac and pulmonary intrafraction motion data during SBRT delivery. This information helps to determine the safety margin required around the target volume. ${ }^{25,27}$

\section{Clinical Approach to STAR}

\section{Imaging and mapping of the arrhythmia substrate}

Localizing the arrhythmogenic substrate before radiotherapy of VT is essential for efficacy and safety. The standard 12-lead ECG provides clues regarding the origin of the tachyarrhythmia. Anatomic ventricular scar can be localized using imaging modalities such as cardiac MRI, positron emission tomography-CT, or cardiac ultrasound/echocardiography. Scar identification remains challenging and can be limited because of cardiac devices such as implantable cardioverter defibrillators (ICDs). Endocardial voltage and arrhythmogenic substrate information from a previous catheter electrophysiology study/invasive VT ablation procedure can also be helpful with scar delineation. Before the ablation procedure, the patient undergoes a reference CT scan with a custom immobilization device. The information from the previous scar imaging is used to delineate the target ventricular scar region on the reference CT image.

Recent advancements in noninvasive localization of VT substrates include surface sensors that noninvasively reconstruct electrogram, single-beat potentials, and isochrones on the epicardial surface of the heart. There are different products available with the most commonly known product being CardioInsight's (Medtronic, Minneapolis, MN) electrocardiographic imaging (ECGI). This product uses imaging and an electrode vest to map electrical activity of the epicardial heart surface. ${ }^{28}$ The vest has more than 250 electrodes, which produce body surface recordings. This provides data on activation times, recovery times, and voltage that is then combined with geometry information acquired through CT or MRI. ${ }^{22,28}$ The major limitation of ECGI is that the mapping information is on the basis of epicardial activation, which might not be relevant to tachyarrhythmia with endocardial or septal substrates. ${ }^{22}$ A recent study has also raised concerns about the accuracy of ECGI in epicardial mapping. ${ }^{29}$

\section{STAR protocol}

Using imaging information and mapping/electrical information, the regions of the ventricular scar are first identified. After acquiring the VT substrate location, local anatomy is contoured to provide a 3D GTV. A geometric expansion PTV is then added to the GTV to account for organ and patient movements, inaccuracies in beam and patient setup, and any other uncertainties. Decisions regarding target volume, target dose, and treatment time are made in coordination with electrophysiology, medical physics, radiology, and radiation oncology. Radiation technicians help to secure and match patients with body fixation devices. The STAR procedure is then performed. Current STAR protocols are limited to 1 treatment with an average duration (beam on time) of $<20$ 


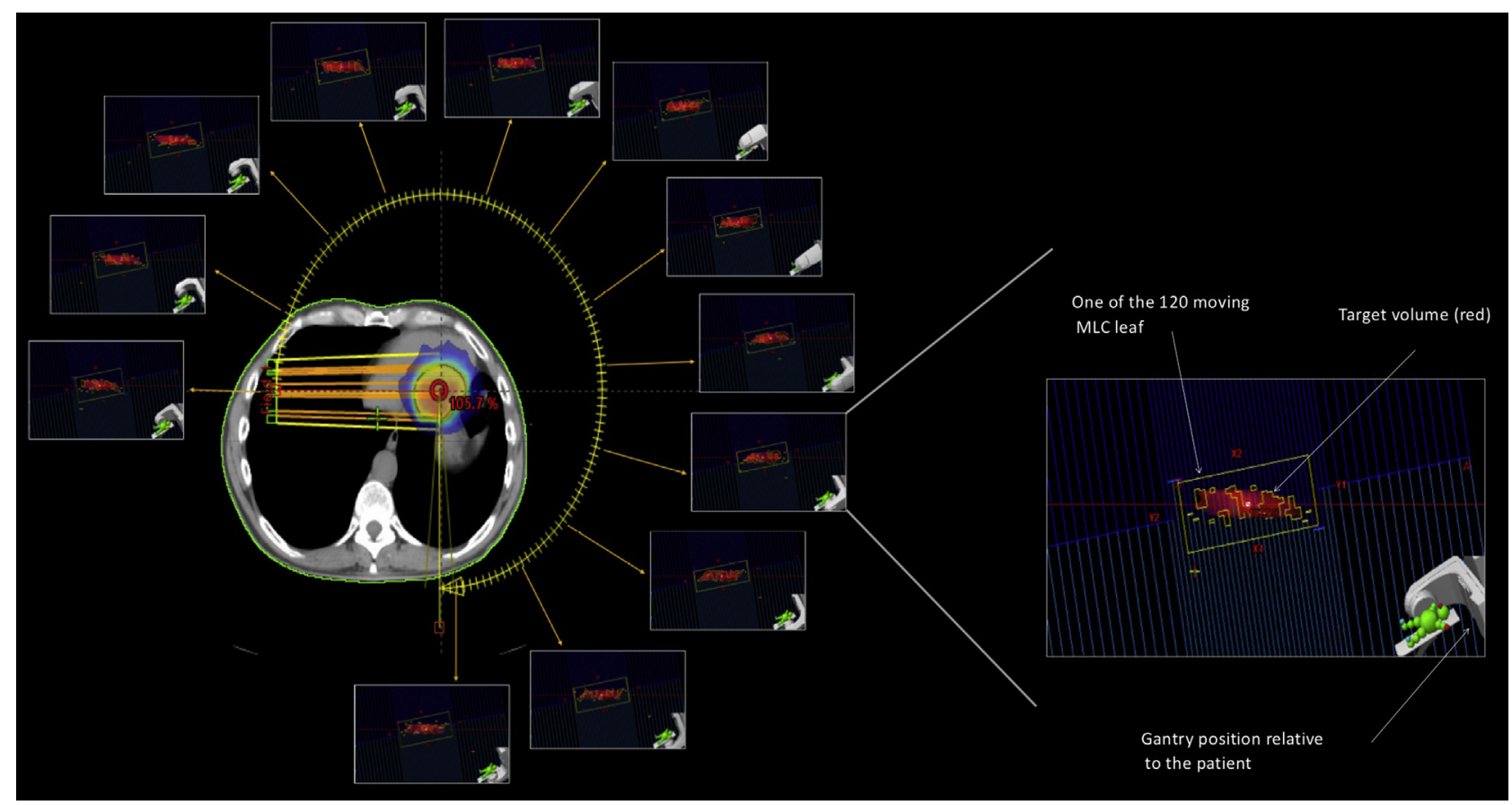

Figure 1. Illustration of volumetric modulated arc therapy (VMAT) delivery. The red contour on the computed tomography image represents the target volume. The colour wash represents the radiation dose delivered to the target volume. The radiation dose is delivered simultaneously by varying 3 parameters during treatment delivery: gantry rotation speed, treatment aperture shape via movement of multileaf collimator (MLC) leaves (shown in each square), and dose rate. Each square represents the specific MLC pattern to deliver a fraction of the dose at that specific gantry angle. Image courtesy of Varian Medical Systems, Inc. All rights reserved

minutes (range, 10-90 minutes depending on the system used). ${ }^{8}$ The optimal radiation dose for VT substrate ablation has yet to be determined. Preclinical studies that previously explored STAR showed a reduction in arrhythmia after administration of 25-35 Gy delivered as a single fraction. This dose has been accompanied by consistent findings of late myocardial fibrosis void of electrical activity. ${ }^{27,30-32}$ Lower doses are beneficial in limiting radiation-induced inflammation, however, there is reportedly inconsistent myocyte cell death. ${ }^{32}$ Dose selection is on the basis of the size and depth of the PTV balanced with risks of adverse events. In other settings of radiotherapy, the dose provided to the heart is kept to the minimum ("as low as reasonably achievable" principle) wherein the volume of the heart that receives 20 Gy should ideally be less than $15 \%$ and the mean dose to the heart should be less than 2 Gy. During radiotherapy for STAR, the dose given to the scar is 20-25 Gy. Ideally, the dose delivered to any $15 \mathrm{cc}$ of the heart mass is limited to $<16 \mathrm{~Gy}$.

The dose distribution is created using inverse planning technique and delivered with either VMAT or intensitymodulated radiation therapy. This technique has very stringent imaging requirements to achieve the highest geometrical accuracy possible and to maximize the dose to the target while sparing nearby organs at risk. ${ }^{8,12,25}$ The inverse planning technique first defines the desired dose distribution. Treatment parameters are then determined to achieve the desired distribution using a complex optimization algorithm by finding a solution to the inverse planning problem. STAR delivery to the thorax can account for respiratory motion by increasing the size of the PTV to be irradiated or by respiratory phase gating, where the beam is only on during a certain phase of respiration. Patients have reported only minimal discomfort during the procedure. Most patients who receive STAR for treatment of VT will have an ICD, which may remain active during the treatment. After STAR, the ICD is checked immediately and at regular intervals thereafter to ensure that there are no changes in sensing or pacing parameters.

\section{STAR}

\section{Feasibility studies}

Feasibility studies for STAR ablation were performed in porcine, canine, and rabbit models. These studies are summarized in Supplemental Table S1. ${ }^{10,12,33-43}$ Anatomical sites of interest included the pulmonary vein and left atrial tissue (as in a pulmonary vein isolation for $\mathrm{AF}$ ), the cavotricuspid isthmus (as in the ablation for typical atrial flutter), the LV free wall (as in the ablation for VT), and the atrioventricular node (as in purposeful production of complete heart block). Treatment planning and results of LV free wall STAR in a porcine model is shown in Figure 2. ${ }^{36}$ These studies evaluated radiation as a cardiac ablation energy source to observe effects on myocardial structure and electrophysiological function that would portend a successful ablation. This also provided information regarding collateral damage to neighbouring 
A

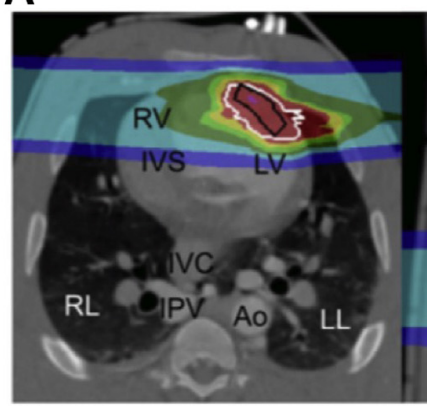

C

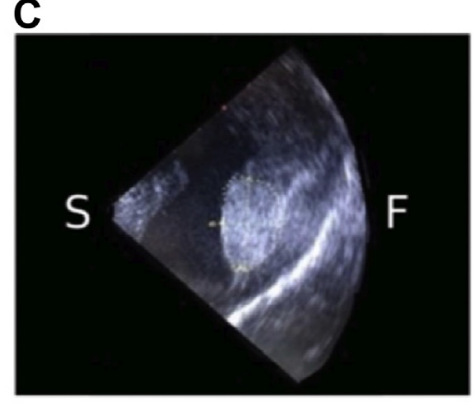

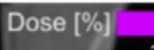

B

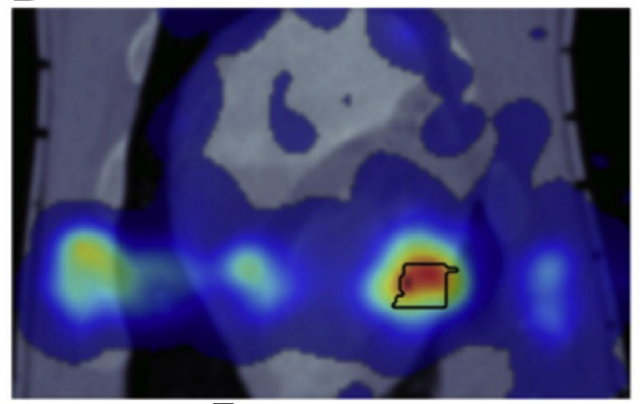

D

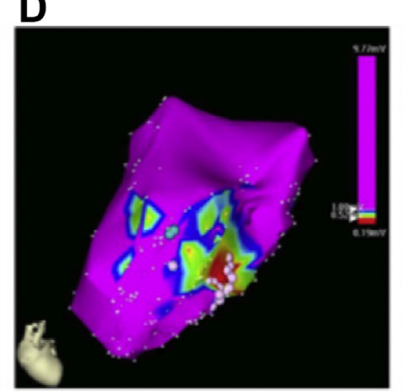

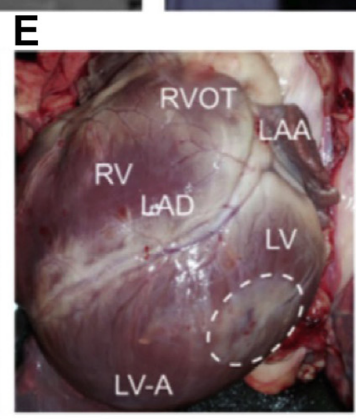

$\mathbf{F}$

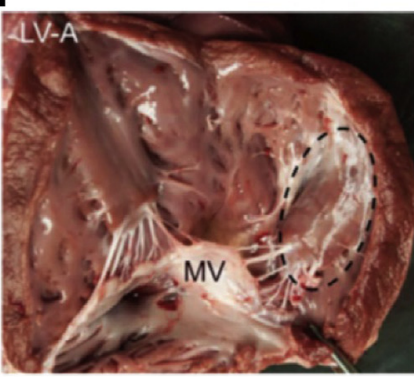

Figure 2. Outcomes after left ventricular free wall irradiation. (A) Transverse and coronal plane of a treatment plan with 2 lateral carbon beams (40 Gy). (B) Anteroposterior view of by-product $\beta+$ activity shown as colour wash. (C) Intracardiac ultrasound image of the left ventricular free wall (F) after irradiation; hyperechoic lesion area marked by dotted lines. (D) Left anterior oblique view of an endocardial voltage map of the left ventricle (LV) 6 months after irradiation; local voltage $>1.0 \mathrm{mV}$ is depicted in magenta, voltage $<0.5 \mathrm{mV}$ depicted in red, and other colours mark voltages in between. White dots indicate fragmented potentials. (E) Macroscopic left ventricular epicardial lesion outcome 6 months after irradiation with the dashed line marking the contoured target zone. (F) Endocardial lesion outcome 6 months after irradiation. Ao, descending aorta; F, Freewall; IPV, inferior pulmonary vein; IVC, inferior vena cava; IVS, interventricular septum; LAA, left atrial appendage; LAD, left anterior descending coronary artery; LL, left lung; LV-A, left ventricular apex; MV, mitral valve; RL, right lung; RV, right ventricle; RVOT, right ventricular outflow tract; S, septal site. Modified from Lehmann et al. under Creative Commons Attribution Attribution 4.0 International (CC BY 4.0). ${ }^{36}$

structure complications and outcomes facilitated subsequent research in human subjects.

\section{Clinical reports}

To date, reports of the use of radioablation of arrhythmogenic substrates in humans have predominantly been limited to the treatment of VT associated with structural heart disease. The approach to STAR in these reports involved imaging of the VT scar substrate and mapping of the putative VT origin (Fig. 3).

The first clinical STAR ablation ${ }^{44}$ was performed in 2012 at Stanford University Medical Center on a 71-year-old man with a severe ischemic cardiomyopathy and drug-refractory VT, who was receiving multiple ICD shocks and was not considered to be a candidate for catheter ablation. Imaging showed LV inferior, inferoseptal, and inferior-lateral scar from base to apex and the morphology of the VT was compatible with an origin in this region. Ablation in this region was performed with external beam radiation (CyberKnife; Accuray Inc, Sunnyvale, CA) using 25 Gy over 90 minutes prescribed to the $75 \%$ isodose line encompassing the inferior, inferoseptal and inferolateral walls. Motion was managed using respiratory tracking. The patient tolerated the procedure well and his monthly number of VT episodes declined from 562 episodes per month (averaged over 2 months before ablation) to 52 episodes per month (averaged over months 2-9 after ablation). The cycle length of the VT was slowed from
380-411 ms to 480 ms. Repeat imaging showed mild extension of, but mostly consolidation of, the preexisting scar with no damage to other regions of the myocardium (Table 1). ${ }^{44}$ This patient died 9 months later with chronic obstructive pulmonary disease respiratory failure, congestive heart failure, and recurrent VT. Subsequently, 2 other case reports have been published ${ }^{31,45}$ that are notable in that they each reported saltatory antiarrhythmic effects within 1 week of STAR, suggesting that the early inflammatory response is as antiarrhythmic as is the later fibrosis response.

Cuculich et al. reported the first case series of patients with refractory VT treated with STAR. ${ }^{25}$ Patients were recruited if they had had at least 3 ICD-treated VT episodes in the previous 3 months despite use of at least 2 antiarrhythmic medications that had failed to be effective, or were not candidates for catheter ablation. Five patients with mean age of 66 years with ischemic or nonischemic cardiomyopathy, New York Heart Association (NYHA) class III or IV heart failure symptoms, and a mean LV ejection fraction of $23 \%$ were treated. VT mapping was performed noninvasively using the ECGI system and anatomical imaging was performed using MRI, single-photon emission computed tomography, CT, or echocardiography. Ablation was performed with photon radiation (TrueBeam; Varian Medical Systems, Palo Alto, CA) with 25 Gy to the PTV prescribed to the $75 \%$ isodose line over a mean irradiation time of 14 minutes with a mean myocardial target volume of 49 cc. Each patient responded with a reduction in VT burden. The total number of VT 


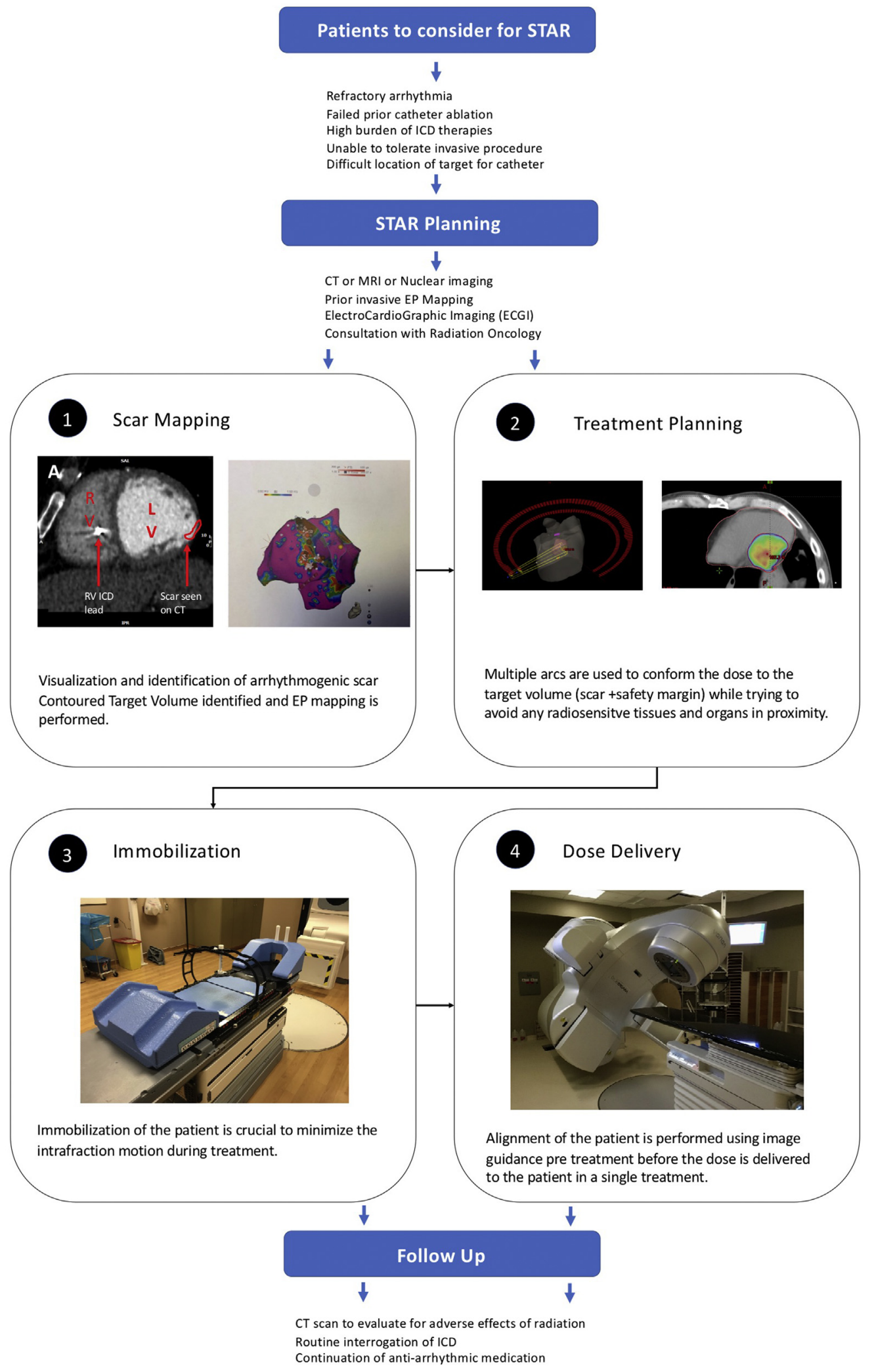

Figure 3. Stereotactic arrhythmia radioablation (STAR) treatment planning and protocol. Patients to consider for STAR followed by planning, delivery, and follow-up. CT, computed tomography; EP, electrophysiology; ICD, implantable cardioverter defibrillator; LV, left ventricle; MRI, magnetic resonance imaging; $\mathrm{RV}$, right ventricle. 


\begin{tabular}{|c|c|c|c|c|c|c|c|c|c|c|c|}
\hline$\overline{\text { Study }}$ & Cvek et al. ${ }^{45}$ & Loo et al. ${ }^{44}$ & Cuculich et al. ${ }^{25}$ & Jumeau et al. ${ }^{31}$ & Haskova et al. ${ }^{49}$ & Robinson et al. ${ }^{27}$ & Zeng et al. ${ }^{50}$ & Neuwirth et al. ${ }^{30}$ & Qian et al. ${ }^{48}$ & Gianni et al. ${ }^{32}$ & Qian et al. ${ }^{51}$ \\
\hline$\overline{\text { Arrythmia }}$ & $\begin{array}{l}\text { Ventricular } \\
\text { tachycardia }\end{array}$ & $\begin{array}{l}\text { Ventricular } \\
\text { tachycardia }\end{array}$ & $\begin{array}{l}\text { Ventricular } \\
\text { tachycardia }\end{array}$ & $\begin{array}{l}\text { Ventricular } \\
\text { tachycardia }\end{array}$ & $\begin{array}{l}\text { Ventricular } \\
\text { tachycardia } \\
\text { Cardiac fibroma }\end{array}$ & $\begin{array}{l}\text { Ventricular } \\
\text { tachycardia }\end{array}$ & $\begin{array}{c}\text { Ventricular } \\
\text { tachycardia } \\
\text { Cardiac lipoma }\end{array}$ & $\begin{array}{l}\text { Ventricular } \\
\text { tachycardia }\end{array}$ & Atrial fibrillation & $\begin{array}{l}\text { Ventricular } \\
\text { tachycardia }\end{array}$ & $\begin{array}{l}\text { Ventricular } \\
\text { tachycardia }\end{array}$ \\
\hline Study size (type) & $\begin{array}{l}\mathrm{N}=1(\text { case } \\
\text { report })\end{array}$ & $\mathrm{N}=1$ (case report) & $\mathrm{N}=5$ (case series) & $\mathrm{N}=1$ (case report) & $\mathrm{N}=1$ (case report) & $\mathrm{N}=19$ (prospective) & $\mathrm{N}=1$ (case report) & $\mathrm{N}=10$ (case series) & $\mathrm{N}=2$ (case series) & $\mathrm{N}=5$ (prospective) & $\mathrm{N}=1$ \\
\hline Age, years & 72 & 71 & $\begin{array}{l}\text { Mean, } 62 \text { (range, 60- } \\
\quad 83 \text { ) }\end{array}$ & 75 & 34 & $\begin{array}{l}\text { Mean, } 66 \text { (range, 49- } \\
81 \text { ) }\end{array}$ & 29 & $\begin{array}{l}\text { Mean, } 66 \text { (range, 61- } \\
\quad 78 \text { ) }\end{array}$ & 53 and 59 & $\begin{array}{l}\text { Mean, } 62.6 \text { (range, } \\
45-76 \text { ) }\end{array}$ & 77 \\
\hline ex & Female & Male & Male, 4; female, 2 & Male & Male & Male, 17 ; female, 2 & Male & Male, 9; female, 1 & Male, 1; female, 1 & Male, 5 & Male \\
\hline $\begin{array}{l}\text { Гype of } \\
\text { cardiomyopathy }\end{array}$ & Nonischemic & Ischemic & $\begin{array}{l}\text { Ischemic, } 2 \text {; } \\
\text { nonischemic, } 3\end{array}$ & Nonischemic & None & $\begin{array}{l}\text { Ischemic; } 11 ; \\
\text { nonischemic, } 8\end{array}$ & None & $\begin{array}{l}\text { Ischemic, } 8 ; \\
\quad \text { nonischemic, } 2\end{array}$ & None & $\begin{array}{l}\text { Ischemic, 4; } \\
\text { nonischemic, } 1\end{array}$ & Ischemic \\
\hline NYHA class & Not reported & Not reported & $\begin{array}{l}\text { III, } 1 \\
\text { IV }, 4\end{array}$ & Not reported & I & $\begin{array}{c}\text { I, } 1 \\
\text { II, } 4 \\
\text { III, } 10 \\
\text { IV, } 4\end{array}$ & I & $\begin{array}{l}\text { II, } 6 \\
\text { III, } 4\end{array}$ & I, 2 & $\begin{array}{l}\text { I, } 1 \\
\text { II, } 4\end{array}$ & Not stated \\
\hline LV function & LVEF $25 \%$ & LVEF $24 \%$ & $\begin{array}{c}\text { LVEF } 23 \text { (range, } \\
15 \%-37 \% \text { ) }\end{array}$ & LVEF $15 \%$ & Normal & $\begin{array}{c}\text { LVEF } 25 \text { (range, } \\
15 \%-58 \%)\end{array}$ & Normal & $\begin{array}{l}\text { LVEF } 26.5 \% \pm \\
\quad 3.2 \%\end{array}$ & Normal & $\begin{array}{l}\text { LVEF 34\% (range, } \\
20 \%-55 \% \text { ) }\end{array}$ & LVEF 15\% \\
\hline AADs & $\beta$-Blocker & $\begin{array}{l}\text { Sotalol } \\
\text { Mexiletine }\end{array}$ & $\begin{array}{l}\geq 3 \text { AADs, } 4 \\
2 \text { AADs, } 1\end{array}$ & Not reported & $\begin{array}{l}\beta \text {-Blocker } \\
\text { Amiodarone }\end{array}$ & $\begin{array}{l}\beta \text {-Blocker, } 18 \\
>1 \text { AAD, } 11\end{array}$ & $\begin{array}{l}\text { Amiodarone } \\
\text { Mexiletine }\end{array}$ & $\begin{array}{l}\beta \text {-Blocker, } 9 \\
\text { Amiodarone, } 2 \\
\text { No AAD, } 1\end{array}$ & $\begin{array}{l}\beta \text {-Blocker, } 2 \\
\text { Amiodarone, } 1 \\
\text { Propafenone, } 1\end{array}$ & $\begin{array}{l}1 \mathrm{AAD}, 2 \\
2 \mathrm{AADs}, 3\end{array}$ & $\begin{array}{l}\text { Amiodarone } \\
\text { Quinidine } \\
\text { Mexiletine }\end{array}$ \\
\hline $\begin{array}{l}\text { Number of previous } \\
\text { ablations }\end{array}$ & $\begin{array}{l}\text { Previous } \\
\quad \text { endocardial and } \\
\text { epicardial RF } \\
\text { ablations }\end{array}$ & None & $\begin{array}{l}2 \text { Patients, } 0 \\
1 \text { Patient, } 4 \\
1 \text { Patient, } 1 \\
1 \text { Patient, } 2\end{array}$ & $\begin{array}{l}\text { Previous RF catheter } \\
\text { ablation }\end{array}$ & Cryoablation & $\begin{array}{l}\text { Median number of } \\
\text { previous catheter } \\
\text { ablations, } 1 \\
\text { (range, } 0-4)\end{array}$ & $\begin{array}{l}3 \text { Percutaneous } \\
\text { ablations } \\
1 \text { Epicardial ablation }\end{array}$ & $\begin{array}{l}3 \text { Patients, } 1 \\
4 \text { Patients, } 2 \\
2 \text { Patients, } 3 \\
1 \text { Patient, } 5\end{array}$ & None & $\begin{array}{l}3 \text { Patients, } 1 \\
2 \text { Patients, } 2\end{array}$ & $\begin{array}{l}\text { Precious RF catheter } \\
\text { ablation }\end{array}$ \\
\hline Treatment planning & $\begin{array}{l}\text { ECG } \\
\text { Previous EP study } \\
\text { CARTO and CT } \\
\text { No additional } \\
\text { margin added } \\
\text { to ITV to make } \\
\text { PTV }\end{array}$ & $\begin{array}{l}\text { ECG, } \\
\text { PET, and } \\
\text { echocardiogram; } \\
\text { PTV delineated by } \\
\text { radiation } \\
\text { oncology }\end{array}$ & $\begin{array}{l}\text { ECG } \\
\text { ECGI* } \\
\text { SPECT or CMR } \\
\text { PTV delineated by } \\
\quad \text { radiation } \\
\quad \text { oncologist }\end{array}$ & $\begin{array}{l}\text { ECG } \\
\text { MRI, PET, and EP } \\
\text { study } \\
\text { ITV with no } \\
\text { additional margin } \\
\text { added }\end{array}$ & $\begin{array}{l}\text { ECG } \\
\text { Previous EP study }\end{array}$ & $\begin{array}{l}\text { ECG } \\
\text { ECGI* } \\
\text { SPECT or CMR } \\
5 \mathrm{~mm} \text { added as safety } \\
\text { margin to form } \\
\text { PTV }\end{array}$ & $\begin{array}{l}\text { ECG } \\
\text { Previous EP study } \\
\text { Internal fiduciary } \\
\quad \text { marker placed } \\
\quad \text { transvenously } \\
\text { Cardiac CT } \\
\text { MultiPlan }\end{array}$ & $\begin{array}{l}\text { ECG } \\
\text { CARTO } \\
\text { ECG-gated CT } \\
\text { No additional margin } \\
\text { for PTV } \\
\text { ICD lead for } \\
\text { respiratory } \\
\text { motion } \\
\text { MultiPlan }{ }^{\dagger} \text { treatment }^{-}\end{array}$ & $\begin{array}{c}\text { Internal fiduciary } \\
\text { marker placed } \\
\text { transvenously } \\
\text { Contrast-enhanced } \\
\text { CT } \\
\text { CyberHeart System } \\
\text { with CardioPlan } \\
\text { software }\end{array}$ & $\begin{array}{l}\text { ECG } \\
\text { CT scan } \\
\text { Placement of } \\
\text { transjugular } \\
\text { temporary active } \\
\text { fixation lead } \\
\text { (fiduciary marker) } \\
\text { CardioPlan } / \\
\text { MultiPlan } \\
\text { treatment }\end{array}$ & $\begin{array}{l}\text { ECG } \\
\text { Previous EP study }\end{array}$ \\
\hline $\begin{array}{l}\text { Treatment volume, } \\
\mathrm{cc}\end{array}$ & Not reported & Not reported & $\begin{array}{l}49.4 \text { (range, } 17.3- \\
81.0 \text { ) }\end{array}$ & 21 & Not reported & $\begin{array}{c}\text { PTV, } 98.9 \text { (range, } \\
\text { 60.9-298.8) }\end{array}$ & 71 & $\begin{array}{l}\text { PTV } 22.2 \text { (range, } \\
14.2-29.6 \text { ) }\end{array}$ & $48.5 / 54.5$ & $\begin{array}{l}\text { PTV } 143 \pm 50 \\
\quad \text { (range, } 80-184)\end{array}$ & Not stated \\
\hline Treatment target & $\begin{array}{l}\text { Base of the lateral } \\
\text { wall of the LV }\end{array}$ & $\begin{array}{l}\text { Inferoseptal, } \\
\text { inferior and } \\
\text { inferolateral wall }\end{array}$ & $\begin{array}{l}\text { Anterior basal, } 2 \\
\text { Inferior, 1 } \\
1 \mathrm{LV} \text { outflow and } \\
\text { septum, 1 } \\
\text { Inferolateral, } 1\end{array}$ & $\begin{array}{l}\text { Posterior to the } \\
\text { anterior segment } \\
\text { of the basal } \\
\text { interventricular } \\
\text { septum }\end{array}$ & $\begin{array}{l}\text { Between septum and } \\
\text { posterior medial } \\
\text { papillary muscle }\end{array}$ & $\begin{array}{l}\text { Anterior, } 5 \\
\text { Lateral, } 6 \\
\text { Inferior, } 6 \\
\text { Septal, } 3 \\
\text { Apex, } 4 \\
\text { LV summit, } 2 \\
\text { RV, } 1\end{array}$ & $\begin{array}{l}\text { LV wall adjacent to } \\
\text { the } \\
\text { interventricular } \\
\text { groove }\end{array}$ & $\begin{array}{l}\text { Anterolateral, } 2 \\
\text { Inferior, } 5 \\
\text { Inferolateral, } 1 \\
\text { Posterobasal, } 2\end{array}$ & Pulmonary vein & $\begin{array}{l}\text { Anterior mid, 1 } \\
\text { Anterior midapical, } \\
\text { septal midapical, } 2 \\
\text { Basal and mid } \\
\text { inferior apical } \\
\text { inferior, 1 } \\
\text { Septal, basal mid, 1 }\end{array}$ & $\begin{array}{l}\text { Anteroseptal and } \\
\text { apical scar } \\
\text { Sparing of the basal } \\
\text { anteroseptum to } \\
\text { preserve ICD } \\
\text { lead, conduction } \\
\text { system and } \\
\text { valvular function }\end{array}$ \\
\hline $\begin{array}{l}\text { Radiation dose } \\
\text { Treatment time }\end{array}$ & $\begin{array}{r}27.6 \text { Gy } \\
114 \text { Minutes }\end{array}$ & $\begin{array}{l}33 \text { Gy } \\
90 \text { Minutes }\end{array}$ & $\begin{array}{c}25 \text { Gy } \\
14 \text { (Range, } 11-18 \\
\text { min) minutes }\end{array}$ & $\begin{array}{l}25 \text { Gy } \\
45 \text { Minutes }\end{array}$ & $\begin{array}{r}25 \text { Gy } \\
\text { Not reported }\end{array}$ & $\begin{array}{c}25 \mathrm{~Gy} \\
15.3 \text { (range, 5.4- } \\
\text { 32.3) minutes }\end{array}$ & $\begin{array}{l}24 \mathrm{~Gy} \times 3 \\
69 \text { Minutes }\end{array}$ & $\begin{array}{c}25 \text { Gy } \\
69 \text { (Range, 45-80) } \\
\text { minutes }\end{array}$ & $\begin{array}{l}25 \text { Gy } \\
90 \text { Minutes }\end{array}$ & $\begin{array}{c}32 \mathrm{~Gy} \\
82 \pm 11 \text { (Range, 66- } \\
92 \text { ) minutes }\end{array}$ & $\begin{array}{l}25 \text { Gy } \\
\text { Not stated }\end{array}$ \\
\hline Equipment & $\begin{array}{l}\text { CyberKnife }^{\dagger} \\
\text { Respiratory gating: } \\
\text { Synchrony } \\
\text { Respiratory } \\
\text { Tracking } \\
\text { Immobilization: } \\
\text { BodyFix }\end{array}$ & $\begin{array}{l}\text { CyberKnife }^{\dagger} \\
\text { Respiratory gating: } \\
\text { Synchrony } \\
\text { Respiratory } \\
\text { Tracking } \\
\text { Immobilization: } \\
\text { BodyFix }\end{array}$ & $\begin{array}{l}\text { TrueBeam }^{\S} \\
\text { Respiratory gating: 4- } \\
\text { dimensional CT } \\
\text { Immobilization: } \\
\text { BodyFix } \\
\text { Cradle }^{\pi} \text {, Alpha }\end{array}$ & $\begin{array}{l}\text { CyberKnife }^{\dagger} \\
\text { Respiratory gating: 4- } \\
\text { dimensional CT } \\
\text { Immobilization: } \\
\text { BodyFix }\end{array}$ & CyberKnife $^{\dagger}$ & $\begin{array}{l}\text { TrueBeam } \\
\text { Respiratory gating: } 4- \\
\text { dimensional CT } \\
\text { Immobilization: } \\
\text { BodyFix } \\
\text { Cradle }^{\S} \text {, Alpha }\end{array}$ & CyberKnife $^{\dagger}$ & $\begin{array}{l}\text { CyberKnife }^{\dagger} \\
\text { Respiratory gating: }^{\text {tracking of ICD }} \\
\text { lead, 4- } \\
\text { dimensional CT } \\
\text { Immobilization: } \\
\text { not stated }\end{array}$ & $\begin{array}{l}\text { CyberKnife }^{\dagger} \\
\text { Respiratory gating: } \\
\text { tracking of ICD } \\
\text { lead } \\
\text { Immobilization: not } \\
\text { stated }\end{array}$ & $\begin{array}{l}\text { CyberKnife }^{\dagger} \\
\text { Respiratory gating: } \\
\text { X-Sight Spine } \\
\text { Tracking System } \\
\text { Synchrony } \\
\text { Respiratory } \\
\text { Tracking } \\
\text { Immobilization: not } \\
\text { stated }\end{array}$ & Not stated \\
\hline $\begin{array}{r}\text { Complications } \\
\text { (immediate) }\end{array}$ & None & None & None & None & None & None & None & Acute nausea $(\mathrm{n}=4)$ & None & None & None \\
\hline
\end{tabular}


duction in median Reducton in $10 \%$ of all beat episodes from 6577 episodes VT during the of VT. VT to $3 \%$ at 10 562 episodes to 6577 episodes
over 15 patientfirst week; free of days; no 2-9 month months to 4 episodes over 46
patient-months

arrhythmia at ICD shocks since

disappeared ove 8

duction in VT $V T$ episodes from from 189 to $0 . \mathrm{N}$ SBRT; no months VT at 4-mont
follow-up electrical storm months post months to (range, $0-31$ ) over 6 months after 6 week blanking period;

improvement in

quality of life at 6 months

$\begin{array}{cccc}\text { No complications } & \text { No echo changes at } & \text { No changes in } \mathrm{LV} & \text { No reported } \\ \text { noted at } 6 & 1,3, \text { and } 6 & \text { function; low- } & \text { complications; } \\ \text { weeks; } ; 0 & \text { months } & \text { grade radiation } & \text { improvement in } \\ \text { pericardial } & & \text { pneumonitis } & \text { LV function } \\ \text { effusion or } & & \text { resolved at } 12 & \\ \text { radiation } & & \text { months; no effects } \\ \text { pneumonitis } & & \text { on ICD system }\end{array}$

\section{No reported}

No acute to

o acute toxicity ICDs during or after SBRT.

1 Heart failure

exacerbation at 65 days

1 Pericarditis

5 Pericardial

effusions

2 Grade II radiatio

pneumonitis

fistula

No clinical or

radiographic
evidence

reduction of

$\mathrm{N}$

of episodes from
18 to $0.93(P=$

$0.012)$; recurrent

electrical storm in

3 patients

Cardiac: $\mathrm{n}=3$

Outcome reported Deceased at $9 \quad$ Fatal CVA 3 months Alive at 4 months

$\begin{array}{ll}\text { only to } 6 \text { weeks; } & \text { months } \\ \text { alive at } 6 \text { weeks } & \text { COPD }\end{array}$

after treatment in
1 patient with $\mathrm{AF}$

not receiving

anticoagulant

- Heart failure a

recurrent VT

(range, 5.5-15

months); pursued

palliative care

Noncardiac: $\mathrm{n}=3$

- Accidental

asphyxiation

- Amiodarone pul-

monary toxicity
- Biliary sepsis

Acute toxicity of
nausea $(\mathrm{n}=4)$

1 Patient with

progression
mitral

regurgitatio

(possible
radiation-related
toiciy)

radiation-rela
toxicity)

No change in LV

function, NT-

proBNP, or

troponin
No effects on ICD

Alive at 4 months

Cardiac: $\mathrm{n}=2$

- Heart failure $(5$

months)

- Heart failure with

refractory VT (18

months)

Noncardiac: $\mathrm{n}=1$

- Vascular dementia

and Alzheimer's

dementia

AAD, antiarrhythmic drug; AF, atrial fibrillation; CARTO, Cartographic Information Division; CMR, cardiac magnetic resonance; COPD, chronic obstructive pulmonary disease; CT, computed tomography; CVA, cerebrovascular accident; ECG, electrocardiogram; ECGI, electrocardiographic imaging; echo, echocardiogram; EP, electrophysiology; ICD, implantable cardioverter defibrillator; ITV, internal target volume; LV, left ventricle; LVEF, left ventricular ejection fraction; MRI, magnetic resonance imaging; NT-proBNP, N-terminal pro b-type natriuretic peptide; NYHA, New York Heart Association; PET, positron emission tomography; PTV, planned target volume; PVC, premature ventricular contractions; RF, radio frequency; RV, right ventricle; SBRT, stereotactic body radiation therapy; SPECT, single-photon emission computed tomography; VT, ventricular tachycardia.

*ECGI from BioSemi BV (Amsterdam, The Netherlands).

${ }^{\dagger}$ MultiPlan software, CyberKnife, Synchrony Respiratory Tracking system, and X-Sight Spine Tracking System from Accuray Inc (Sunnyvale, CA).

${ }^{\ddagger}$ CyberHeart System and CardioPlan software from CyberHeart Inc (Sunnyvale, CA).

${ }^{5}$ TrueBeam from Varian Medical Systems (Palo Alto, CA).

" BodyFix from Elekta (Stockholm, Sweden).

ॠ Alpha Cradle from Smithers Medical Products, Inc (North Canton, OH). 
episodes was reduced from 6577 in the 3 months before ablation (15 patient-months) to 4 episodes of VT over 46 patient-months of follow-up beginning 6 weeks after the ablation-a 99.9\% reduction in VT burden. ${ }^{25}$ The protocol used in STAR ablation is shown in Figure 3. ${ }^{25}$ The same group then went on to perform the Electrophysiology-Guided Non-invasive Cardiac Radioablation for Ventricular Tachycardia (ENCORE-VT) trial.

The ENCORE-VT trial was a single-arm, prospective, phase I/II trial involving 19 patients. ${ }^{27,46}$ Patients were recruited after $\geq 3$ episodes of sustained monomorphic VT or with premature ventricular contractions (PVC)-related cardiomyopathy and a PVC burden $>20 \%$ after failure of at least 1 antiarrhythmic drug and failure of (or contraindication to) at least 1 catheter ablation procedure. Procedural work flow was similar to that described by Cuculich et al. ${ }^{25}$ with anatomic scar imaging using MRI, single-photon emission computed tomography, or positron-emission tomography-CT and noninvasive VT mapping using ECGI. STAR was delivered with 25 Gy (TrueBeam; Varian Medical Systems) over a median irradiation time of 15 minutes with a mean myocardial target volume of $25 \mathrm{cc}$. The median number of VT episodes was reduced from 119 (range, 4-292) in the 6 months before ablation to 3 (range, $0-31 ; P<0.001$ ) over the subsequent 6 months after ablation excluding a 6-week blanking period. ${ }^{27}$ In 2 patients with PVC-related cardiomyopathy, 24-hour PVC burden was reduced from $24 \%$ to $2 \%$ and from $26 \%$ to $9 \%$, respectively, over 6 months with an improvement in LV function. Use of dual antiarrhythmic medication decreased from $59 \%$ to $12 \%$ of patients $(P=$ 0.008 ) and quality of life improved. ${ }^{27}$ Survival was $89 \%$ at 5 months and $72 \%$ at 12 months. Three deaths were due to recurrent VT, which could reflect a nondurable treatment effect, incomplete VT substrate ablation, or progression of the disease. 27,46

STAR has recently also been reported to be successful as a rescue modality for refractory ventricular electrical storm in a patient for whom traditional catheter ablation had failed. ${ }^{31}$ VT/VF was absent 1 week after therapy without recurrence 4 months after therapy. ${ }^{31}$

Neuwirth et al. reported a case series of 10 ICD patients with NYHA II or III heart failure symptoms, refractory scarrelated VT (predominately due to ischemic cardiomyopathy) in whom previous catheter ablation attempts, which included delineation of the location of the substrate(s) for VT, had failed. ${ }^{30}$ Three-dimensional electroanatomic voltage maps (CARTO, New York, NY) were obtained and myocardial scar was defined by a voltage $<0.5 \mathrm{mV}$. Sites of potential interest for ablation identified using pace-mapping or slowconduction channels were tagged on the electroanatomical maps. Clinical target volume was planned considering the electroanatomic maps supplemented with CT imaging gated to systole and to diastole. Respiratory compensation was performed using the existing ICD lead as a surrogate marker of cardiac motion. No additional margins of uncertainty were added to the internal tumour volume. Ablation was delivered using a CyberKnife (Accuray Inc) radiosurgery system in a single session using $25 \mathrm{~Gy}$ prescribed to the $75 \%$ isodose line over a mean of 68 minutes (range, 45-80 minutes) with a mean PTV of $22.2 \mathrm{~mL}$ (range, 14.2-29.6 mL), a mean conformality index of 1.28 (range, 1.15-1.78), and a mean homogeneity index of 1.24 (range, 1.19-1.52). The median follow-up was 28 months (range, 16-52 months). VT recurred after a 90-day blanking period in 8 of the 10 patients. Nevertheless, there was an $87.6 \%$ reduction in VT burden with the median number of episodes decreased from 18 to $0.93(P=0.012)$ over 28 months. Electrical storm recurred in 3 patients. Three patients died; 2 from heart failure and 1 from a noncardiac cause. ${ }^{30}$

Gianni et al. reported a prospective study of 5 patients with NYHA class I/II heart failure symptoms and refractory scarrelated VT (predominant ischemic cardiomyopathy; left ventricular ejection fraction, $34 \pm 15 \%)$ in whom antiarrhythmic drug therapy and catheter ablation had failed. ${ }^{32}$ Tranjugular insertion of a pacemaker lead was used as a fiduciary marker with contrast-enhanced CT scans using MultiPlan software (Accuray Inc, Sunnyvale, CA) to map a PTV target of $143 \pm 50$ cc. A CyberKnife (Accuray Inc) radiosurgery system was used to deliver $25 \mathrm{~Gy}$ prescribed to the $75 \%$ isodose line over a mean of 82 minutes. Follow-up at 6 months showed a marked reduction in VT burden in 4 of the 5 subjects; however, all had clinically significant VT recurrences by 10-14 months of follow-up. ${ }^{32}$ Methodologic differences have been suggested as a cause for these negative results in that the other series had more extensive preprocedural imaging to identify ventricular scar and/or noninvasive ECG body surface mapping. ${ }^{47}$

The first report of STAR for pulmonary vein isolation for AF was published by Qian et al. in 2019. ${ }^{48}$ Results from 2 ambulatory patients with paroxysmal AF despite $\geq 1$ antiarrhythmic medication who had not previously undergone invasive catheter ablation were reported. An internal fiduciary marker was placed transvenously and attached to the interatrial septum for treatment planning and respiratory motion tracking. ${ }^{48}$ Contrast-enhanced CT with $3 \mathrm{D}$ and contouring strategy (CardioPlan; CyberHeart Inc, Sunnyvale, CA) were used to identify the treatment target. A CyberKnife (Accuray Inc) radiosurgery system was used to deliver 25 Gy over 90 minutes with a PTV of 49-54 mL. One patient had recurrence of AF (now persistent) after 6 months of follow-up; the other remained arrhythmia-free after 2 years of follow-up. ${ }^{48}$

In 2 case reports, Haskova et al. ${ }^{49}$ and Zeng et al. ${ }^{50}$ reported the use of STAR for the treatment of VT related to cardiac tumours (a fibroma and a lipoma, respectively) each having failed resection and catheter ablation. In each case there was a significant reduction of VT burden.

Incomplete STAR therapy has been associated with recurrent VT. STAR delivery sparing of the anteroseptal focus of an arrhythmogenic scar with goals of preserving the ICD lead, conduction system, and valvular function resulted in a recurrence of VT at 4 months requiring catheter ablation. ${ }^{51}$

\section{Adverse effects}

Cuculich et al. reported no complications of STAR during the index hospitalization in their 5 patients, although $3 \mathrm{pa}-$ tients reported fatigue 1-3 days after treatment. ${ }^{25}$ Nevertheless, CT scanning after 3 months identified inflammatory lung changes consistent with radiation-induced pneumonitis. ${ }^{23}$ These changes resolved by the 12-month follow-up examination. ${ }^{25}$ ICD performance, lead thresholds, and impedances 
were unchanged. No worsening heart failure or change in LV systolic function was found. One patient with $\mathrm{AF}$ who was not anticoagulated suffered a fatal cerebrovascular accident. Although this was presumed to be a thromboembolic complication of AF, a thromboembolic risk of STAR has not been excluded. ${ }^{25}$ Cardiac pathology of this patient showed prominent ectatic blood vessels at the target site without evidence of acute vasculitis or edema. ${ }^{25}$

No acute toxicity was observed in ENCORE-VT. Nevertheless, delayed pericarditis occurred in $28 \%$ of the 19 patients and grade 2 radiation pneumonitis occurred in $11 \%$ of the patients in the 90 days after STAR. ${ }^{27}$ These rates are consistent with those of SBRT for the treatment of lung cancer. ${ }^{46}$ One patient was hospitalized 65 days after treatment with worsening heart failure and another was hospitalized after 80 days with pericarditis that resolved with prednisone. Interrogation of the ICDs revealed normal performance. One patient died of a noncardiac cause; autopsy was declined. ${ }^{27}$ Recent long-term follow-up identified 1 case of gastropericardial fistula requiring surgical repair. ${ }^{52}$

Neuwirth et al. reported that 4 of the 10 patients in their series experienced nausea related to acute radiation toxicity. Each of these 4 patients had a target volume delivered to the inferior LV, close to the stomach. One patient with previous mitral regurgitation had a notable progression of mitral regurgitation and changes in valvular morphology 17 months after STAR. ${ }^{30}$ There was increased posterior leaflet restriction due to fibrotic changes to the leaflet and annulus that might have represented grade 3 late radiation-related toxicity. ${ }^{30} \mathrm{~A}$ recently published review including these studies reported $>85 \%$ reduction in VT burden with shortterm safety. ${ }^{53}$

Two-year follow-up from the STAR for AF case series revealed no adverse events at 2 years. Mean delivered dose of radiation to nearby tissues was as high as $18.5 \mathrm{~Gy}$ to the mitral valve. ${ }^{48}$ Follow-up cardiac MRI showed evidence of new fibrosis. However, LV function was preserved. ${ }^{48}$

\section{Adverse effects of radiotherapy in other settings}

Studies of thoracic radiation in other settings show that over the long term, radiation can affect all parts of the heart. ${ }^{26,54,55}$ The most commonly affected structures are the pericardium and coronary arteries with development of telangiectasia followed by thrombotic, inflammatory, and fibrotic changes. ${ }^{26}$ Radiation-induced pericardial disease is expressed as pericarditis with effusion, fibrosis, and constriction. Pericarditis can be acute or delayed for months to years. ${ }^{26}$ Radiation is thought to accelerate atherosclerosis by inducing inflammation resulting in endothelial damage. ${ }^{26}$ Meta-analyses of studies with lower doses of mediastinal radiation report relative risks of myocardial infarction ranging from 1.5 to 3.0 times over 8.25 years. ${ }^{26,56}$ Most patients who have had thoracic radiation exhibit no valvular dysfunction over 98 months. ${ }^{26}$ Heart failure, an uncommon adverse effect of radiation, typically presents with a restrictive profile. ${ }^{26}$ There are also case reports of myocarditis and conduction disturbances. However, these events are relatively uncommon.

Injury of tissues adjacent to the heart is still an important concern after thoracic radiation. Lung, esophagus, trachea, and the phrenic nerve are just a few of the important structures at risk. Gastrointestinal toxicity, in the form of stomach fistula and/or perforation, has also been reported by early adopters of this technique as an infrequent but potentially lifethreatening complication. Careful attention to the dose delivered to the stomach as well as verification of stomach position using cone beam CT is recommended before treatment delivery.

\section{Implementation and Future Direction}

The equipment for stereotactic radiation therapy of malignancies is widely available; 11,568 such devices are active worldwide. ${ }^{9}$ This availability facilitates rapid implementation of STAR ablation with minimal incremental cost. Although no economic analysis has been published, it is conceivable that STAR ablation for VT might be more cost-effective than catheter ablation because of its short treatment time and noninvasive nature. Currently there are studies that support short-term safety and efficacy. However, which patients might benefit from this novel treatment remains to be determined. Future research is needed in studying the long-term effects of STAR while optimizing noninvasive scar localization and a standardized protocol for radiation delivery.

The application of STAR ablation will require collaboration between radiation oncology, medical physics, radiology, cardiology, cardiac electrophysiology, and many groups of allied health professionals. ${ }^{96}$ Multidisciplinary involvement is necessary to select the most appropriate patients and optimize STAR planning and treatment.

\section{Which Patients to Consider?}

Most procedures performed to date were for refractory ventricular arrhythmias in a frail patient population for whom repeat or advanced catheter ablation techniques were not applicable. At this time, with the expertise and knowledge regarding invasive catheter ablation, STAR should be considered on a compassionate basis and, preferably, as part of a clinical trial. As documented in the most recent clinical trials, this modality might be most helpful to reduce morbidity of patients who suffer frequent ICD therapies.

To date, STAR has been used in research settings or in refractory patients approaching palliation. At this time, it has not been approved by regulatory agencies and is not covered by insurance groups.

\section{Conclusions}

Preclinical studies have shown the potential application of STAR to many cardiac tachyarrhythmias. Nevertheless, to date, the clinical application of STAR has been focused on patients with refractory VT. This treatment has been shown to be effective and to have short-term safety. Thus, STAR presents a noninvasive treatment modality for patients with cardiac tachyarrhythmias who are unable to tolerate or in whom traditional treatment approaches have failed. STAR has the potential to be a substantial advancement in interventional cardiac electrophysiology, especially if it is proven to be safe and effective in the treatment of multiple different cardiac tachyarrhythmias. 


\section{Methods of Study Review}

For our review, we used 4 search engines: PubMed, ScienceDirect, Scopus, and Google Scholar. Our keywords included "external beam radiation, cardiac arrhythmia, stereotactic arrhythmia radio ablation (STAR), radioablation, ventricular tachycardia, and radiosurgery." We separated the results of our search into animal and clinical studies with the later further divided into case reports and prospective studies. Summaries of these studies are presented in Supplemental Table S1 and Table 1.

\section{Funding Sources}

Funding for this work was provided by Libin Cardiovascular Institute of Alberta.

\section{Disclosures}

The authors have no conflicts of interest to disclose.

\section{References}

1. Priori SG, Blomström-Lundqvist C, Mazzanti A, et al. 2015 ESC guidelines for the management of patients with ventricular arrhythmias and the prevention of sudden cardiac death: The Task Force for the Management of Patients with Ventricular Arrhythmias and the Prevention of Sudden Cardiac Death of the European Society of Cardiology (ESC) endorsed by: Association for European Paediatric and Congenital Cardiology (AEPC). Europace 2015;17:1601-87.

2. Antzelevitch C, Burashnikov A. Overview of basic mechanisms of cardiac arrhythmia. Card Electrophysiol Clin 2011;3:23-45.

3. Connolly SJ, Dorian P, Roberts RS, et al. Comparison of $\beta$-blockers, amiodarone plus $\beta$-blockers, or sotalol for prevention of shocks from implantable cardioverter defibrillators: the OPTIC study: a randomized trial. JAMA 2006;295:165-71.

4. Kumar S, Androulakis AFA, Sellal JM, et al. Multicenter experience with catheter ablation for ventricular tachycardia in lamin A/C cardiomyopathy. Circ Arrhythm Electrophysiol 2016;9:e004357.

5. Bhaskaran A, Chik W, Thomas S, Kovoor P, Thiagalingam A. A review of the safety aspects of radio frequency ablation. Int J Cardiol Heart Vasc 2015;8:147-53.

6. Bohnen M, Stevenson WG, Tedrow UB, et al. Incidence and predictors of major complications from contemporary catheter ablation to treat cardiac arrhythmias. Heart Rhythm 2011;8:1661-6.

7. Gupta A, Perera T, Ganesan A, et al. Complications of catheter ablation of atrial fibrillation. Circ Arrhythm Electrophysiol 2013;6:1082-8.

8. John RM, Stevenson WG. Noninvasive ablation of ventricular tachycardia. N Engl J Med 2017;377:2388-90.

9. Zei PC, Soltys S. Ablative radiotherapy as a noninvasive alternative to catheter ablation for cardiac arrhythmias. Curr Cardiol Rep 2017;19:79.

10. Lehmann HI, Deisher AJ, Takami M, et al. External arrhythmia ablation using photon beams: ablation of the atrioventricular junction in an intact animal model. Circ Arrhythm Electrophysiol 2017;10:e004304.

11. Connell PP, Hellman S. Advances in radiotherapy and implications for the next century: a historical perspective. Cancer Res 2009;69:383-92.

12. Sharma A, Wong D, Weidlich G, et al. Noninvasive stereotactic radiosurgery (CyberHeart) for creation of ablation lesions in the atrium. Heart Rhythm 2010;7:802-10.
13. Attix F. Ionizing Radiation. Introduction to Radiological Physics and Radiation Dosimetry. Hoboken, NJ: Wiley, 1986.

14. Kim MS, Kim W, Park IH, et al. Radiobiological mechanisms of stereotactic body radiation therapy and stereotactic radiation surgery. Radiat Oncol J 2015;33:265-75.

15. Park HJ, Griffin RJ, Hui S, Levitt SH, Song CW. Radiation-induced vascular damage in tumors: implications of vascular damage in ablative hypofractionated radiotherapy (SBRT and SRS). Radiat Res 2012;177: $311-27$.

16. Ramadan R, Vromans E, Anang DC, et al. Single and fractionated ionizing radiation induce alterations in endothelial connexin expression and channel function. Sci Rep 2019;9:4643.

17. Hu ZI, McArthur HL, Ho AY. The abscopal effect of radiation therapy: what is it and how can we use it in breast cancer? Curr Breast Cancer Rep 2017;9:45-51.

18. Sheu T, Molkentine J, Transtrum MK, et al. Use of the LQ model with large fraction sizes results in underestimation of isoeffect doses. Radiother Oncol 2013;109:21-5.

19. Baskar R, Lee KA, Yeo R, Yeoh KW. Cancer and radiation therapy: current advances and future directions. Int J Med Sci 2012;9:193-9.

20. Teoh M, Clark CH, Wood K, Whitaker S, Nisbet A. Volumetric modulated arc therapy: a review of current literature and clinical use in practice. Br J Radiol 2011;84:967-96.

21. Chang BK, Timmerman RD. Stereotactic body radiation therapy: a comprehensive review. Am J Clin Oncol 2007;30:637-44.

22. Kim EJ, Davogustto G, Stevenson WG, John RM. Non-invasive cardiac radiation for ablation of ventricular tachycardia: a new therapeutic paradigm in electrophysiology. Arrhythm Electrophysiol Rev 2018;7: 8-10.

23. Tong Y, Yin Y, Lu J, et al. Quantification of heart, pericardium, and left ventricular myocardium movements during the cardiac cycle for thoracic tumor radiotherapy. Onco Targets Ther 2018;11:547-54.

24. Javadi S, Eckstein J, Ulizio V, et al. Evaluation of the use of abdominal compression of the lung in stereotactic radiation therapy. Med Dosim 2019;44:365-9.

25. Cuculich PS, Schill MR, Kashani R, et al. Noninvasive cardiac radiation for ablation of ventricular tachycardia. N Engl J Med 2017;377:2325-36.

26. Yusuf SW, Sami S, Daher IN. Radiation-induced heart disease: a clinical update. Cardiol Res Pract 2011;2011:317659.

27. Robinson CG, Samson PP, Moore KM, et al. Phase I/II trial of electrophysiology-guided noninvasive cardiac radioablation for ventricular tachycardia. Circulation 2019;139:313-21.

28. Rudy Y. Noninvasive ECG imaging (ECGI): mapping the arrhythmic substrate of the human heart. Int J Cardiol 2017;237:13-4.

29. Duchateau J, Sacher F, Pambrun T, et al. Performance and limitations of noninvasive cardiac activation mapping. Heart Rhythm 2019;16:435-42.

30. Neuwirth R, Cvek J, Knybel L, et al. Stereotactic radiosurgery for ablation of ventricular tachycardia. Europace 2019;21:1088-95.

31. Jumeau R, Ozsahin M, Schwitter J, et al. Rescue procedure for an electrical storm using robotic non-invasive cardiac radio-ablation. Radiother Oncol 2018;128:189-91.

32. Gianni C, Rivera D, Burkhardt JD, et al. Stereotactic arrhythmia radioablation for refractory scar-related ventricular tachycardia. Heart Rhythm 2020;17:1241-8. 
33. Perez-Castellano N, Villacastín J, Aragoncillo P, et al. Pathological effects of pulmonary vein $\beta$ radiation in a swine model. Journal of cardiovascular electrophysiology 2006;17:662-9.

34. Gardner EA, Sumanaweera TS, Blanck O, et al. In vivo dose measurement using TLDs and MOSFET dosimeters for cardiac radiosurgery. J Appl Clin Med Phys 2012;13:190-203.

35. Blanck O, Bode F, Gebhard M, et al. Dose-escalation study for cardiac radiosurgery in a porcine model. Int J Radiat Oncol Biol Phys 2014;89: 590-8.

36. Lehmann HI, Graeff C, Simoniello P, et al. Feasibility study on cardiac arrhythmia ablation using high-energy heavy ion beams. Sci Rep 2016;6: 38895 .

37. Zei PC, Wong D, Gardner E, Fogarty T, Maguire P. Safety and efficacy of stereotactic radioablation targeting pulmonary vein tissues in an experimental model. Heart Rhythm 2018;15:1420-7.

38. Lehmann IH, Richter MD, Prokesch BH, et al. Atrioventricular node ablation in Langendorff-perfused porcine hearts using carbon ion particle therapy: methods and an in vivo feasibility investigation for catheter-free ablation of cardiac arrhythmias. Circ Arrhythm Electrophysiol 2015;8:429-38.

39. Refaat MM, Ballout JA, Zakka P, et al. Swine atrioventricular node ablation using stereotactic radiosurgery: methods and in vivo feasibility investigation for catheter-free ablation of cardiac arrhythmias. J Am Heart Assoc 2017;6:e007193.

40. Amino M, Yoshioka K, Tanabe T, et al. Heavy ion radiation up-regulates Cx43 and ameliorates arrhythmogenic substrates in hearts after myocardial infarction. Cardiovasc Res 2006;72:412-21.

41. Amino M, Yoshioka K, Fujibayashi D, et al. Year-long upregulation of connexin 43 in rabbit hearts by heavy ion irradiation. Am J Physiol 2010;298:H1014.

42. Amino M, Yoshioka K, Furusawa Y, et al. Inducibility of ventricular arrhythmia 1 year following treatment with heavy ion irradiation in dogs with myocardial infarction. Pacing Clin Electrophysiol 2017;40:379-90.

43. Hohmann S, Deisher AJ, Suzuki A, et al. Left ventricular function after noninvasive cardiac ablation using proton beam therapy in a porcine model. Heart Rhythm 2019;16:1710-9.

44. Loo BW Jr, Soltys SG, Wang L, et al. Stereotactic ablative radiotherapy for the treatment of refractory cardiac ventricular arrhythmia. Circ Arrhythm Electrophysiol 2015;8:748-50.

45. Cvek J, Neuwirth R, Knybel L, et al. Cardiac radiosurgery for malignant ventricular tachycardia. Cureus 2014;6:e190.

46. Zei PC, Mak R. Noninvasive stereotactic radioablation for ventricular tachycardia ENCORE-VT (EP-Guided Noninvasive Cardiac
Radioablation): is the sequel as good as the original? Circulation 2019;139:322-4.

47. Dewland TA, Wong AC, Gerstenfeld EP. Noninvasive ventricular tachycardia ablation: should we apply the accelerator or the brake? Heart Rhythm 2020;17:1249-50.

48. Qian PC, Azpiri JR, Assad J, et al. Noninvasive stereotactic radioablation for the treatment of atrial fibrillation: first-in-man experience. J Arrhythm 2019;36:67-74.

49. Haskova J, Peichl P, Pirk J, et al. Stereotactic radiosurgery as a treatment for recurrent ventricular tachycardia associated with cardiac fibroma. HeartRhythm Case Rep 2018;5:44-7.

50. Zeng LJ, Huang LH, Tan H, et al. Stereotactic body radiation therapy for refractory ventricular tachycardia secondary to cardiac lipoma: a case report. Pacing Clin Electrophysiol 2019;42:1276-9.

51. Qian PC, Quadros K, Aguilar M, et al. Recurrent ventricular tachycardia arising at the treatment borderzone after stereotactic radioablation in a patient with ischemic cardiomyopathy. Europace 2020;22:1053.

52. Robinson CG, Moore KM, Samson PP, Cuculich PS. Management of radiation-related complications after noninvasive cardiac radioablation (abstract). Heart Rhythm Society 2020. Scientific Sessions eabstracts:DAB08-3.

53. van der Ree MH, Blanck O, Limpens J, et al. Cardiac radioablation-a systematic review. Heart Rhythm 2020;17:1381-92.

54. Veinot JP, Edwards WD. Pathology of radiation-induced heart disease: a surgical and autopsy study of 27 cases. Hum Pathol 1996;27: 766-73.

55. Brosius FC III, Waller BF, Roberts WC. Radiation heart disease: analysis of 16 young (aged 15 to 33 years) necropsy patients who received over 3 , 500 rads to the heart. Am J Med 1981;70:519-30.

56. Cuzick J, Stewart H, Rutqvist L, et al. Cause-specific mortality in longterm survivors of breast cancer who participated in trials of radiotherapy. J Clin Oncol 1994;12:447-53.

57. Felipe de Campos-Lobato L, Vogel JD. Enterocutaneous fistula associated with malignancy and prior radiation therapy. Clin Colon Rectal Surg 2010;23:176-81.

\section{Supplementary Material}

To access the supplementary material accompanying this article, visit CJC Open at https://www.cjcopen.ca/ and at https://doi.org/10.1016/j.cjco.2020.11.006. 